\title{
Observações sobre o diagnóstico laboratorial e a epidemiologia da leishmaniose tegumentar no Estado do Paraná, sul do Brasil
}

\author{
Observations on laboratory diagnosis and cutaneous leishmaniasis \\ epidemiology in the State of Paraná, South of Brazil \\ Thaís Gomes Verzignassi Silveira1, Sandra Mara Alessi Aristides Arraes1, \\ Dennis Armando Bertolini1, Ueslei Teodoro1, Maria Valdrinez Campana \\ Lonardoni1, Andréa Claudia Bekner Silva Roberto1, Miria Ramos1, \\ Antonio Nerilo Sobrinho1, Edna Ishikawa2 e Jeffrey Shaw2 3
}

\begin{abstract}
Resumo De 1986 a 1997 foram encaminhados ao Laboratório de Ensino e Pesquisa em Análises Clínicas, da Universidade Estadual de Maringá, 1418 pacientes suspeitos de leishmaniose tegumentar para diagnóstico laboratorial. Os testes utilizados foram a intradermorreação de Montenegro, reação de imunofluorescência indireta, pesquisa direta, isolamento e identificação de Leishmania. Destes pacientes, 955 (67,3\%) apresentaram pelo menos um dos testes positivo, entre os quais 804 (84,2\%) contraíram a infecção no Estado do Paraná, 665 (69,6\%) tinham de 15 a 49 anos de idade, 658 (68,9\%) eram do sexo masculino, 523 (54,8\%) foram diagnosticados nos 3 primeiros meses de evolução da lesão e 74 (7,7\%) apresentavam comprometimento nasobucofaríngeo. Dos 83 municípios do Estado do Paraná envolvidos, destacaram-se São Jorge do Ivaí (10,2\%), Doutor Camargo (9,8\%), Terra Boa (7,3\%), Maringá (7,3\%), Jussara (6,0\%) e Cianorte (4,5\%). Foram isoladas 77 cepas de Leishmania (Viannia) braziliensis, predominando (63,6\%) o serodema 1.
\end{abstract}

Palavras-chaves: Leishmaniose tegumentar. Epidemiologia. Leishmania sp. Diagnóstico.

\begin{abstract}
Between 1986 and 1997 a total of 1418 patients were examined at the Clinical Analysis Teaching and Research Laboratory of Maringá State University (LEPAC/UEM) for cutaneous leishmaniasis by direct examination of stained smears made from the lesions, the Montenegro skin test and the indirect immunofluorescent antibody test. Nine hundred and fifty five patients (67.3\%) were positive for at least one of the three tests and of these 804 (84.2\%) were considered to have contracted the disease in Paraná State; 665 (69.6\%) were between 15 and 49 years old; 658 (68.9\%) were males; 523 (54.8\%) sought medical advice during the first three months of their infections and $74(7.7 \%)$ had mucosal lesions. Of the 83 counties of Paraná State, where the patients had most probably acquired their infections, $44.7 \%$ were from the counties of São Jorge do Ivaí (10.2\%), Doutor Camargo (9.8\%), Terra Boa (7.3\%), Maringá (7.3\%), Jussara (6.0\%) and Cianorte (4.5\%). Seventy seven strains of Leishmania (Viannia) braziliensis were isolated and $63.6 \%$ of these strains belong to serodema 1 .
\end{abstract}

Key-words: Cutaneous leishmaniais. Epidemiology. Diagnosis. Paraná State. Brazil.

\footnotetext{
1. Departamento de Análises Clínicas da Universidade Estadual de Maringá, Maringá, PR; 2. Departamento de Parasitologia do Instituto Evandro Chagas, Fundação Nacional de Saúde, Belém, PA; 3. Departamento de Parasitologia do Instituto de Ciências Biológicas, Universidade de São Paulo, São Paulo, SP;

Apoio financeiro: Secretaria de Estado da Saúde do Paraná, Laboratório de Ensino e Pesquisa em Análises Clínicas da Universidade Estadual de Maringá, Núcleo de Estudos em Saúde Coletiva, Fundação Nacional de Saúde e Wellcome Trust.

Endereço para correspondência: Dr ${ }^{\mathrm{a}}$ Thaís Gomes Verzignassi Silveira. Depto de Análises Clínicas/CCS/UEM Av. Colombo 5790, 87020-900 Maringá, PR, Brasil. Fax: 5544 261-4490

E-mail: tgvsilve@dac.uem.br

Recebido para publicação em 29/4/97.
} 
A leishmaniose tegumentar americana (LTA) é uma doença endêmica em vários Estados do Brasil8 com número crescente de notificações, somando mais de 300 mil casos entre 1980 e 1996671129 . No Estado do Paraná esta dermatose também é endêmica20, atingindo proporções epidêmicas em 1993, 1994 e 1995 com 819, 1361 e 962 casos notificados, respectivamente ${ }^{19}$. A LTA é uma doença que preocupa os órgãos responsáveis pela saúde, principalmente pela possibilidade do desenvolvimento de lesões mutilantes envolvendo mucosa nasal, bucal e faríngea16. O aumento do número de casos de leishmaniose tegumentar no Brasil requer cuidados imediatos que privilegiem o preparo de profissionais da área de saúde para a identificação da doença e o suprimento de recursos laboratoriais e medicamentos, pois a deficiência destes fatores têm prejudicado o diagnóstico e tratamento adequados da doença12 15. Em áreas endêmicas, o diagnóstico de leishmaniose tegumentar na maioria das vezes ainda é clínico, sujeito a erros que podem ser reduzidos com auxílio de métodos parasitológicos e imunológicos.

Este trabalho descreve aspectos clínicos, laboratoriais e epidemiológicos observados a partir do atendimento de 1418 pacientes suspeitos de leishmaniose tegumentar, encaminhados ao Laboratório de Ensino e Pesquisa em Análises Clínicas da Universidade Estadual de Maringá (LEPAC/UEM), para diagnóstico, no período de 1986 a 1997.

\section{MATERIAL E MÉTODOS}

Foram avaliadas as informações e os resultados de testes laboratoriais de 1418 pacientes portadores de lesão cutânea ou mucosa, com suspeita clínica de leishmaniose tegumentar, atendidos pelo LEPAC/UEM no período de abril de 1986 a dezembro de 1997.

As seguintes informações foram obtidas dos pacientes: nome, sexo, idade, endereço, características do domicílio e peridomicílio, tipo de atividade profissional, tempo de evolução da lesão, local provável onde ocorreu a infecção, atividade que exercia no momento mais provável da infecção, tipo e localização das lesões e recidivas.

Entre os pacientes que apresentavam lesão cutânea colheu-se material da lesão através de biópsia de borda ou escarificação da borda interna, com estilete de ponta biselada, após limpeza com água oxigenada 10 vol. Este material foi usado para a confecção de esfregaços por aposição (biópsia) ou em forma de elipse (escarificação) em lâminas de vidro que foram fixadas com metanol e coradas pelo método de Giemsa. Nos casos em que a pesquisa do parasita em lâmina foi positiva, o material de lesão foi inoculado em meio Blood Agar Base (Difco) contendo 10\% de sangue total desfibrinado de coelho, e/ou triturado em gral de porcelana e inoculado nas patas posteriores de hamsters, para posterior isolamento do parasita em meio de cultura. As cepas isoladas foram enviadas ao Instituto Evandro Chagas, Belém, Pará para serem criopreservadas e identificadas por meio de anticorpos monoclonais.

A identificação das amostras de Leishmania foi feita com um painel de 23 anticorpos monoclonais (B2, B5, B11, B12, B13, B18, B19, M2, T3, D13, M11, M12, CO1, CO2, CO3, L1 doado pela Dra D McMahon-Pratt; WIC 79.3 doado pelo Dr D Snary; N2, N3, LA2, V1, WH1, WA2 - doados pela Dr ${ }^{a}$ CA Hanham) de acordo com a técnica de imunofluorescência descrita por Shaw et al21 e as amostras foram classificadas em serodemas como definido por Shaw et al22.

Para a intradermorreação de Montenegro (IDRM), utilizou-se antígeno fornecido pelo Instituto Adolfo Lutz (IAL) ou preparado no LEPAC/UEM1. Os reagentes foram utilizados conforme recomendação dos fornecedores. Foram consideradas positivas as reações cujo diâmetro médio foi igual ou superior a $6 \mathrm{~mm}$.

A reação de imunofluorescência indireta (IFI) foi realizada segundo Guimarães et al10. O antígeno foi preparado com Leishmania (Viannia) braziliensis, cultivada em Blood Agar Base com sangue de coelho. Os parasitas foram lavados, formolizados e liofilizados 23 . O conjugado antiimunoglobulina G humana - isotiocianato de fluoresceína (Biolab) foi padronizado segundo Camargo 4 . Os soros dos pacientes foram diluídos em Solução Salina Tamponada com fosfato (SST) a partir de 1/20 em razão 2, para determinação do título. Foram considerados positivos títulos iguais ou superiores a 4023 . Em todos os experimentos incluiu-se soro humano normal diluído a 1/20 como controle negativo e soros humanos positivos diluídos como o soro dos pacientes.

A análise estatística foi feita pelo software Microstat II, utilizando teste de proporções ao nível de significância $\mathrm{P}<0,05$. 


\section{RESULTADOS}

O número de pacientes atendidos pelo LEPAC/UEM para diagnóstico de leishmaniose tegumentar no período de 1986 a 1997 foi 1418 , dos quais 23(1986), 112 (1987), 90 (1988), 55 (1989), 40 (1990), 44 (1991), 240 (1992), 173 (1993), 209 (1994), 180 (1995), 145 (1996) e 107 (1997), destes, 955 (67,3\%) apresentaram pelo menos um dos resultados laboratoriais positivo.

$\mathrm{Na}$ Tabela 1 observa-se a distribuição dos 1418 pacientes conforme os resultados obtidos do exame parasitológico de material de lesão, da intradermorreação de Montenegro e da reação de imunofluorescência indireta, para o diagnóstico da leishmaniose tegumentar. Foram considerados negativos 463 pacientes que apresentaram as seguintes combinações de resultados do exame parasitológico, da IDRM e da IFI:

Parasitológico negativo; IDRM negativo; IFI negativo $=217$

Parasitológico não realizado; IDRM negativo; IFI negativo $=97$

Parasitológico não realizado; IDRM negativo; IFI não realizado $=2$

Parasitológico negativo; IDRM não realizado; IFI negativo $=98$

Parasitológico não realizado; IDRM não realizado; IFI negativo $=45$

Tabela 1 - Resultados dos exames parasitológico, Intradermorreação de Montenegro (IDRM) e Imunofluorescência Indireta (IFI) de 1418 pacientes atendidos no Laboratório de Ensino e Pesquisa em Análises Clínicas da Universidade Estadual de Maringá para diagnóstico de leishmaniose tegumentar, de 1986 a 1997.

\begin{tabular}{|c|c|c|c|c|c|}
\hline \multirow[b]{2}{*}{ Parasitológico } & \multirow[b]{2}{*}{ IFI } & \multicolumn{4}{|c|}{ IDRM } \\
\hline & & positivo & negativo & não realizado & total \\
\hline & positivo & $296^{\star}$ & $6^{*}$ & $38^{*}$ & 340 \\
\hline Positivo & negativo & $89^{*}$ & $10^{*}$ & $10^{*}$ & 109 \\
\hline \multirow[t]{2}{*}{$(n=453)$} & não realizado & $1^{*}$ & $0^{*}$ & $3^{*}$ & 4 \\
\hline & positivo & $137^{*}$ & $19^{*}$ & $27^{*}$ & 183 \\
\hline Negativo & negativo & $126^{*}$ & 217 & 98 & 441 \\
\hline \multirow[t]{2}{*}{$(n=629)$} & não realizado & $1^{*}$ & 1 & 3 & 5 \\
\hline & positivo & $66^{*}$ & $7^{*}$ & $15^{*}$ & 88 \\
\hline Não realizado & negativo & $102^{*}$ & 97 & 45 & 244 \\
\hline$(n=336)$ & não realizado & $2^{*}$ & 2 & 0 & 4 \\
\hline Total & 820 & 359 & 239 & 1418 & \\
\hline
\end{tabular}

* Pacientes considerados com diagnóstico laboratorial positivo para leishmaniose tegumentar = 955.

Parasitológico negativo; IDRM não realizado; IFI não realizado $=3$

Parasitológico negativo; IDRM negativo: IFI não realizado $=1$.

Foram considerados com diagnóstico laboratorial positivo os 955 pacientes que apresentaram resultado positivo em pelo menos um dos testes utilizados.

Dentre os 955 pacientes com diagnóstico laboratorial positivo, o exame parasitológico foi realizado em 763 , dos quais $453(59,4 \%)$ foram positivos; a IDRM em 862, sendo positiva em $820(95,1 \%)$ e a IFI em 948 pacientes, sendo que $611(64,4 \%)$ pacientes apresentaram título maior ou igual a 40 (Tabela 1).
$\mathrm{Na}$ Tabela 2, observa-se que dentre os pacientes com exame parasitológico positivo, a IDRM foi realizada em 402, sendo positiva em 386 $(96,0 \%)$. Dos 283 pacientes que apresentaram exame parasitológico negativo, a IDRM foi positiva em 264 (93,3\%). Entre os 650 pacientes com IDRM positiva o parasitológico também foi positivo em 386 (59,4\%). Entre os pacientes com IDRM negativa, o exame parasitológico foi positivo em $16(45,7 \%)$.

Dentre os pacientes com exame parasitológico de lesão positivo (Tabela 2), a IFI foi realizada em 449, sendo positiva em 340 (75,7\%). Dos 309 pacientes com o exame parasitológico de lesão negativo a IFI foi positiva em 183 (59,2\%). Dos 
523 pacientes com IFI positiva, o exame parasitológico foi positivo em 340 (65,0\%). E dentre os 235 pacientes com IFI negativa o exame parasitológico foi positivo em 109 (46,4\%).

Tabela 2 - Resultados dos exames parasitológico, intradermorreação de Montenegro (IDRM), imunofluorescência indireta (IFI) e associações destas técnicas, em pacientes com diagnóstico laboratorial positivo para leishmaniose tegumentar.

\begin{tabular}{|c|c|c|c|}
\hline \multirow[b]{2}{*}{ Parasitológico } & \multicolumn{2}{|c|}{ IDRM } & \multirow[b]{2}{*}{ Total } \\
\hline & positivo & negativo & \\
\hline Positivo & 386 & 16 & 402 \\
\hline Negativo & 264 & 19 & 283 \\
\hline \multirow[t]{2}{*}{ Total } & 650 & 35 & 685 \\
\hline & \multicolumn{2}{|c|}{ Parasitológico } & \\
\hline IFI & positivo & negativo & Total \\
\hline Positivo & 340 & 183 & 523 \\
\hline Negativo & 109 & 126 & 235 \\
\hline \multirow[t]{2}{*}{ Total } & 449 & 309 & 758 \\
\hline & \multicolumn{2}{|c|}{ IFI } & \\
\hline IDRM & positivo & negativo & Total \\
\hline Positivo & 499 & 317 & 816 \\
\hline Negativo & 32 & 10 & 42 \\
\hline Total & 531 & 327 & 858 \\
\hline
\end{tabular}

A IDRM foi mais sensível que a IFI tanto no grupo de pacientes com exame parasitológico positivo quanto negativo ( $p<0,01)$.

Observa-se na Tabela 2 que nos 816 pacientes com IDRM positiva a IFI foi positiva em 499 $(61,2 \%)$, e que entre aqueles $42 \mathrm{com}$ IDRM negativa a IFI foi positiva em 32 (76,2\%). Entre os 531 pacientes com IFI positiva, a IDRM também foi positiva em 499 (94,0\%). Já entre aqueles 327 com IFI negativa a IDRM foi positiva em 317 $(96,9 \%)$.

O resultado obtido pela associação das técnicas exame parasitológico/IDRM mostra positividade de $97,2 \%$ (666/685) (Tabela 2); com a associação exame parasitológico/IFI a positividade foi de $83,4 \%(632 / 758)$ na (Tabela 2) e alcançou $98,8 \%$ (848/858) quando foram associadas as técnicas de IFI/IDRM (Tabela 2).

Na Figura 1, são apresentados os resultados da IDRM e da IFI, em relação ao tempo de evolução da lesão nos 401 pacientes sabidamente portadores de LTA. Observa-se que com menos de 1 mês de evolução da lesão $97,6 \%$ dos pacientes tinham a IDRM positiva e em $68,3 \%$ foram detectados títulos de anticorpos iguais ou superiores a 40. Para os pacientes com lesão de até 3 meses de evolução a positividade da IDRM foi de $96,5 \%$ e da IFI foi de $77,8 \%$.

Dos 955 pacientes que apresentaram diagnóstico laboratorial positivo 114 (11,9\%) recorreram ao laboratório para diagnóstico quando a lesão ainda não havia completado 1 mês de evolução; 236 (24,7\%) quando a lesão tinha entre 1 e 2 meses e $173(18,1 \%)$ entre 2 e 3 meses. Assim, 523 (54,8\%) pacientes procuraram diagnóstico laboratorial nos 3 primeiros meses de evolução da lesão.

$\mathrm{Na}$ Tabela 3, encontra-se a distribuição dos 955 pacientes com diagnóstico laboratorial positivo para LTA, segundo o sexo e a faixa etária. Destes, 658 (68,9\%) eram do sexo masculino. A faixa etária mais atingida foi a de 15 a 49 anos, com 665 (69,7\%) pacientes de ambos os sexos.

A Tabela 4, mostra os municípios do Estado do Paraná onde provavelmente ocorreram as infecções. Entre estes municípios destacaramse São Jorge do Ivaí com 82 (10,2\%), Doutor Camargo com 79 (9,8\%), Terra Boa com 59 (7,3\%), Maringá com 59 (7,3\%), Jussara com 48 $(6,0 \%)$ e Cianorte com $36(4,5 \%)$, que juntos perfizeram $363(45,1 \%)$ casos do total de 804 casos diagnosticados no LEPAC/UEM, de provável infecção no Estado do Paraná.

Na Tabela 5, verifica-se que dos 804 pacientes com diagnóstico laboratorial positivo e que provavelmente infectaram-se no Paraná, 557 $(69,3 \%)$ tinham profissão relacionada à área rural ou residiam em área rural, 227 (28,2\%) eram de área urbana e de 20 (2,5\%) não foi possível 

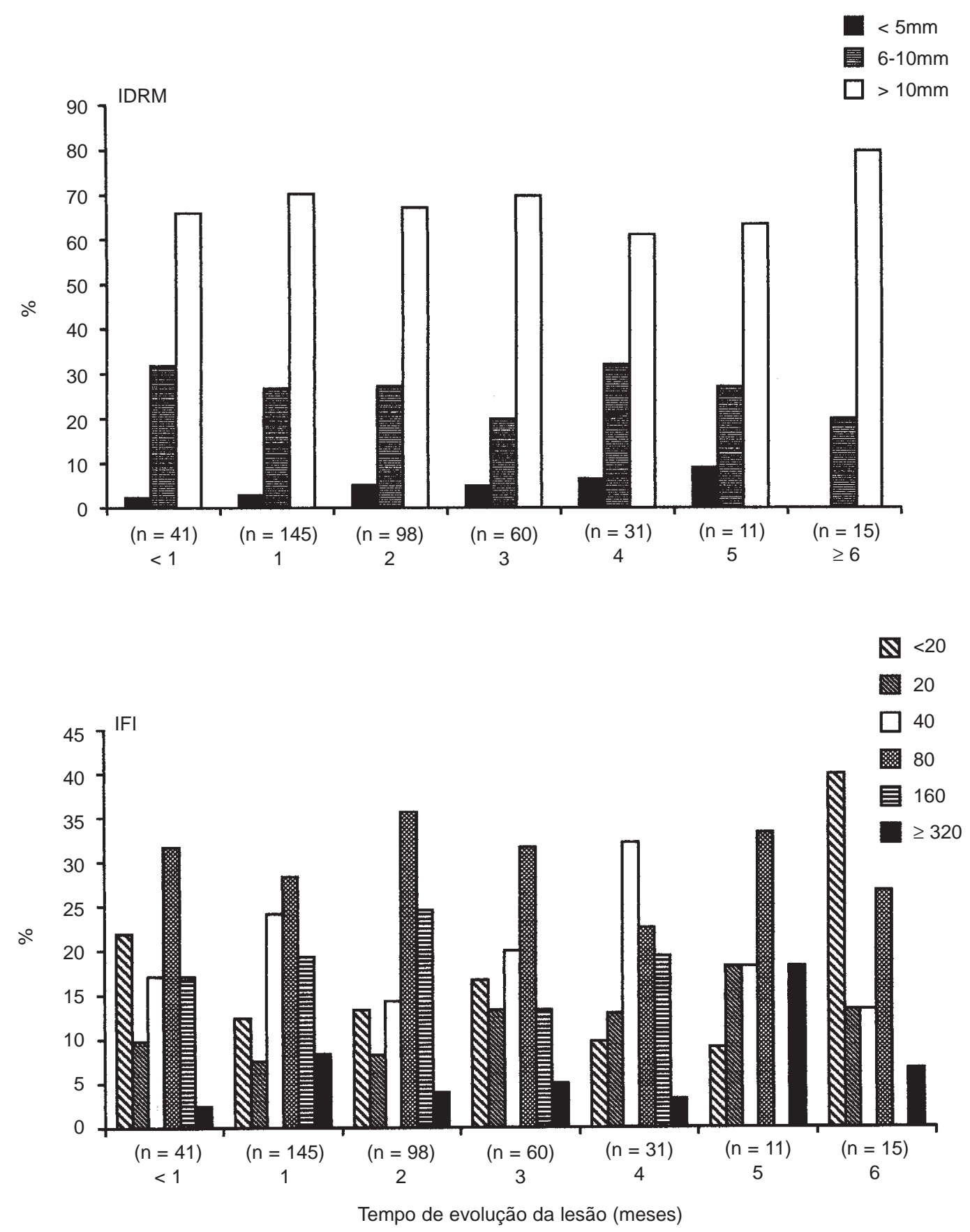

Figura 1 - Percentagem de resultados positivos da intradermorreacão de Montenegro (IDRM) e da reação de imunofluorescência indireta (IFI), em relação ao tempo de evolução das lesões, nos 401 pacientes com parasitológico positivo. 
Tabela 3 - Sexo e idade dos pacientes com diagnóstico laboratorial positivo para leishmaniose tegumentar, atendidos no Laboratório de Ensino e Pesquisa em Análises Clínicas da Universidade Estadual de Maringá, de 1986 a 1997.

\begin{tabular}{|c|c|c|c|c|c|c|}
\hline \multirow{2}{*}{$\begin{array}{c}\text { Faixa etária } \\
\text { (anos) }\end{array}$} & \multicolumn{4}{|c|}{ Sexo } & \multirow[b]{2}{*}{ Total } & \multirow[b]{2}{*}{$\%$} \\
\hline & masculino & $\%$ & feminino & $\%$ & & \\
\hline $0-14$ & 40 & 4,2 & 42 & 4,4 & 82 & 8,6 \\
\hline $15-29$ & 185 & 19,4 & 87 & 9,1 & 272 & 28,5 \\
\hline $30-49$ & 298 & 31,2 & 95 & 10,0 & 393 & 41,2 \\
\hline$\geq 50$ & 132 & 13,8 & 73 & 7,6 & 205 & 21,4 \\
\hline ND & 3 & 0,3 & - & - & 3 & 0,3 \\
\hline Total & 658 & 68,9 & 297 & 31,1 & 955 & 100,0 \\
\hline
\end{tabular}

$\mathrm{ND}=$ não determinado.

Tabela 4 - Número de casos e municípios onde provavelmente ocorreram as infecções dos pacientes com diagnóstico laboratorial positivo para leishmaniose tegumentar, atendidos no Laboratório de Ensino e Pesquisa em Análises Clínicas da Universidade Estadual de Maringá de 1986 a 1997.

\begin{tabular}{|c|c|c|c|}
\hline Municípios do Paraná & № de casos & Municípios do Paraná & № de casos \\
\hline Alto Paraná & 3 & Maringá & 59 \\
\hline Ângulo & 7 & Munhoz de Melo & 5 \\
\hline Assaí & 1 & Nossa Senhora das Graças & 2 \\
\hline Assis Chateubriand & 1 & Nova Esperança & 34 \\
\hline Astorga & 2 & Nova Olímpia & 1 \\
\hline Atalaia & 6 & Ourizona & 11 \\
\hline Bandeirantes & 1 & Paiçandu & 6 \\
\hline Barbosa Ferraz & 1 & Paraíso do Norte & 1 \\
\hline Borrazópolis & 1 & Paranacity & 7 \\
\hline Cambira & 1 & Paranapoema & 11 \\
\hline Campina da Lagoa & 1 & Paranavaí & 3 \\
\hline Campo Mourão & 2 & Peabirú & 5 \\
\hline Cerro Azul & 1 & Pérola & 1 \\
\hline Cianorte & 36 & Porecatu & 1 \\
\hline Cidade Gaúcha & 2 & Porto Rico & 3 \\
\hline Colorado & 24 & Presidente Castelo Branco & 11 \\
\hline Corbélia & 1 & Quinta do Sol & 5 \\
\hline Corumbataí & 2 & Roncador & 1 \\
\hline Cruzeiro do Oeste & 1 & Rondon & 1 \\
\hline Cruzeiro do Sul & 16 & Santa Fé & 12 \\
\hline Diamante do Norte & 2 & Santa Inês & 1 \\
\hline Doutor Camargo & 79 & Santo Inácio & 2 \\
\hline Engenheiro Beltrão & 10 & São Carlos do Ivaí & 2 \\
\hline Floraí & 6 & São Jorge do Ivaí & 82 \\
\hline Floresta & 8 & São Pedro do Ivaí & 2 \\
\hline Flórida & 2 & São Tomé & 5 \\
\hline Goioerê & 2 & Sarandi & 8 \\
\hline Guaíra & 1 & Terra Boa & 59 \\
\hline Icaraíma & 1 & Terra Rica & 2 \\
\hline Iguaraci & 2 & Toledo & 1 \\
\hline Iguaraçu & 2 & Tuneiras do Oeste & 1 \\
\hline Inajá & 8 & Uniflor & 15 \\
\hline Indianópolis & 1 & Umuarama & 1 \\
\hline Itaguajé & 2 & Não determinado & 32 \\
\hline Itambé & 10 & Subtotal & 804 \\
\hline Ivaté & 1 & & \\
\hline Ivatuba & 32 & Outros Estados/País & \\
\hline Jaguapitã & 1 & Acre & 1 \\
\hline Jandaia do Sul & 1 & Amazonas & 1 \\
\hline Janiópolis & 1 & Bahia & 1 \\
\hline Japurá & 5 & Mato Grosso & 45 \\
\hline Jardim Olinda & 1 & Mato Grosso do Sul & 11 \\
\hline Jesuítas & 2 & Minas Gerais & 1 \\
\hline Jussara & 48 & Pará & 1 \\
\hline Loanda & 1 & Rondônia & 18 \\
\hline Lobato & 25 & Santa Catarina & 1 \\
\hline Mamborê & 1 & São Paulo & 18 \\
\hline Mandaguaçu & 30 & Paraguai & 5 \\
\hline Mandaguari & 4 & Não determinado & 48 \\
\hline Marialva & 12 & Total & 955 \\
\hline
\end{tabular}


determinar a profissão e moradia. Segundo relato dos 557 pacientes relacionados à área rural, $115(20,6 \%)$ provavelmente infectaram-se em atividades de lazer como caça, pesca ou acampamento, $246(44,2 \%)$ durante o trabalho, $167(30,0 \%)$ no domicílio ou peridomicílio e 29 $(5,2 \%)$ não souberam informar. Dos 227 que tinham profissão relacionada à área urbana ou residiam em área urbana, 119 (52,4\%) provavelmente adquiriram a infecção em atividades de lazer, $15(6,6 \%)$ durante o trabalho, $45(19,8 \%)$ no peridomicílio e $48(21,1 \%)$ não souberam informar.

Tabela 5 - Atividade, profissão e moradia dos pacientes, autóctones do Estado do Paraná, com diagnóstico laboratorial positivo para leishmaniose tegumentar, atendidos no Laboratório de Ensino e Pesquisa em Análises Clínicas da Universidade Estadual de Maringá, de 1986 a 1997.

\begin{tabular}{|c|c|c|c|c|c|}
\hline \multirow{3}{*}{ Atividade* $^{*}$} & \multicolumn{3}{|c|}{ Profissão e/ou moradia } & & \\
\hline & rural & urbana & não determinado & \multicolumn{2}{|c|}{ Total } \\
\hline & $\mathrm{n}^{0}$ & $\mathrm{n}^{0}$ & $\mathrm{n}^{0}$ & $\mathrm{n}^{\circ}$ & $\%$ \\
\hline Lazer: pesca, caça ou acampamento & 115 & 119 & 2 & 236 & 29,4 \\
\hline Trabalho & 246 & 15 & 0 & 261 & 32,4 \\
\hline Domiciliar/peridomiciliar & 167 & 45 & 0 & 212 & 26,4 \\
\hline Não souberam informar & 29 & 48 & 18 & 95 & 11,8 \\
\hline Total & 557 & 227 & 20 & 804 & \\
\hline
\end{tabular}

* atividade provável quando adquiriu a infecção, conforme relato espontâneo do paciente.

Dos pacientes que provavelmente infectaramse no Estado do Paraná, $263(32,7 \%)$ tinham um ou mais tipos de animais domésticos como cães, galinhas, suínos e eqüídeos próximos à habitação.

As partes do corpo atingidas por lesões foram os membros inferiores em $395(49,1 \%)$ pacientes, os membros superiores em 202 $(25,1 \%)$, a cabeça em $110(13,7 \%)$ e o tronco em $77(9,6 \%)$.

Entre os 955 pacientes com diagnóstico laboratorial positivo, $74(7,7 \%)$ apresentavam comprometimento nasobucofaríngeo. A idade destes pacientes variou de 17 a 87 anos, 44 $(59,5 \%)$ deles eram do sexo masculino e o tempo de evolução do comprometimento nasobucofaríngeo variou de 1 mês a 56 anos. A idade que estes pacientes tinham no início das manifestacões nasobucofaríngeas variou de 1 a 75 anos. Dos 74 pacientes, $16(21,6 \%)$ relataram, no momento da investigação, que não tiveram lesões cutâneas anteriormente e não relataram a presença de cicatrizes que sugerissem a doença. De 46 pacientes que afirmaram terem tido lesões cutâneas foi possível determinar a época em que elas ocorreram em 42 deles. O intervalo entre a lesão cutânea e o início do comprometimento nasobucofaríngeo foi de 0 a 41 anos, sendo que $14(30,4 \%)$ tiveram comprometimento nasobucofaríngeo no período de dois anos após a lesão cutânea e $23(50,0 \%)$ após dez anos. Quarenta e sete pacientes relataram o município onde provavelmente foram infectados e desses, $29(61,7 \%)$ infectaram-se no Estado do Paraná. Com relação aos exames laboratoriais, a IDRM foi realizada em 70 pacientes sendo que $69(98,6 \%)$ apresentaram diâmetro médio maior ou igual a $6 \mathrm{~mm}$. Dos 74 pacientes com comprometimento nasobucofaríngeo, 31 (41,9\%) não apresentaram títulos de anticorpos detectáveis pela IFI, em 12 $(16,2 \%)$ o título foi 20 , em $13(17,6 \%)$ foi 40 , em 9 $(12,2 \%)$ foi 80 , em $6(8,1 \%)$ foi 160 e em $3(4,1 \%)$ foi 320 ou superior. Portanto, em 43 (58,1\%) pacientes os títulos foram inferiores a 40 .

Dos pacientes com lesão cutânea foram isoladas 92 cepas de Leishmania. Das amostras isoladas de pacientes que provavelmente tenham se infectado no Estado do Paraná, 77 foram identificadas como L.(V.) braziliensis. Dentre estas amostras, 49 pertencem ao serodema 1; 2 ao serodema 2; 24 ao serodema 3; 1 ao serodema 7 e 1 a um novo serodema desta espécie. Também foi isolada e identificada uma cepa de Leishmania (Leishmania) amazonensis25. Das 3 amostras de pacientes que provavelmente infectaram-se no Estado do Mato Grosso, 2 pertencem ao serodema 1 e uma pertence ao serodema 3. A amostra isolada de paciente que provavelmente infectou-se em Rondônia não é Leishmania (Viannia) guyanensis mas pertence ao complexo guyanensis. A amostra do paciente que provavelmente infectou-se em Roraima pertence ao serodema 7 de L.(V.) braziliensis. 


\section{DISCUSSÃO}

A leishmaniose tegumentar é comprovadamente endêmica no Estado do Paraná24 263233 , constituindo um problema de saúde pública como em diversos Estados do Brasil10. A primeira notificação de leishmaniose tegumentar no Estado do Paraná foi feita por Rabello apud Silveira et al25. Pessôa e Barreto registraram diversos casos de leishmaniose tegumentar no início da década de 4018. Na década de 50 Miranda e Schweidson 17 e Lima et al13 voltaram a registrar casos de leishmaniose tegumentar neste Estado. Esta dermatose passou a ser notificada oficialmente no Paraná a partir de 1980 (SUCAM)28, mantendo-se endêmica. Contudo, nos anos de 1992, 1993 e 1994 a leishmaniose tegumentar atingiu dimensões epidêmicas, com respectivamente 690,819 e 1.350 casos autóctones registrados ${ }^{19}$.

Guimarães et al ${ }^{9}$, no Vale Ribeira do Iguape, no Estado de São Paulo, assinalaram a doença em crianças de 6 a 14 anos e em adultos, igualmente distribuída entre indivíduos do sexo feminino e masculino e entre trabalhadores rurais e donas de casa. Barreto et al2 no Estado da Bahia, também verificaram que a doença incidia em pessoas de ambos os sexos, porém não atingia crianças. No presente trabalho verificouse que a doença ocorre em crianças $(8,6 \%)$ e mulheres $(31,1 \%)$. Este fato reforça as observações da literatura9 26 de ocorrência da infecção no domicílio e peridomicílio. Entre os pacientes que provavelmente se infectaram no Estado do Paraná e trabalhavam e/ou residiam em área urbana, a maioria (119 ou 52,4\%) referiuse a atividades de lazer que envolviam risco de infecção (principalmente pesca). Entre os que trabalhavam em zona rural, 246 (44,2\%) mencionaram o trabalho como provável atividade de risco e $167(30,0 \%)$ infectaram-se provavelmente no domicílio ou peridomicílio. A ocorrência de infecção em $212(26,4 \%)$ pacientes no domicílio ou peridomicílio pode estar relacionada à presença de animais domésticos próximos à habitação humana. Dentre estes pacientes com infecção adquirida no Estado do Paraná, 263 (32,7\%) referiram-se à presença de animais domésticos nos ambientes domiciliar e peridomiciliar. Assim, estes animais poderiam, além de servirem como fonte de sangue para os flebotomíneos, estarem, assim como o homem, servindo de hospedeiros acidentais de Leishmania sp. Ressalta-se que em área endêmica no norte do Paraná, já foram identificados três cães com a infecção ${ }^{14}$ e 18,2\% dos cães investigados apresentavam sorologia positiva para leishmaniose 27 . Além disso, elevado número de flebotomíneos tem sido coletado no peridomicílio, sobretudo em abrigos de animais domésticos 3031 .

No presente trabalho foram encontrados, através da reação de IFI, títulos significativos de anticorpos em 64,4\% (611/948) dos pacientes considerados com diagnóstico laboratorial positivo para leishmaniose tegumentar, ou seja naqueles que apresentaram resultado positivo em pelo menos um dos testes utilizados. Estes resultados são semelhantes aos obtidos por Guimarães et al9, que detectaram títulos de anticorpos iguais ou superiores a 40 em $66,3 \%$ dos pacientes com diagnóstico clínico para leishmaniose tegumentar, usando a técnica de ELISA. Barreto et al2 verificaram que a IFI era positiva em $51,4 \%$ dos pacientes com lesões ativas e IDRM positiva, enquanto, neste trabalho, $61,2 \%$ (499/816) das reações de IFI foram positivas em indivíduos portadores de lesão e com IDRM positiva.

Neste trabalho verificou-se que, entre as técnicas utilizadas para o diagnóstico laboratorial positivo para LTA, a IDRM apresentou positividade de $95,1 \%$, seguindo-se a IFI de $64,4 \%$ e o parasitológico de 59,4\%. Também foi observado que a associação entre IFI e IDRM, alcançou uma positividade de $98,8 \%$ e a do parasitológico e IDRM uma positividade de $97,2 \%$. Estes resultados permitem sugerir que, na impossibilidade da utilização das três técnicas, a IDRM seja sempre associada com a IFI ou com o parasitológico para diagnósticos mais seguros.

Dentre os pacientes seguramente portadores de LTA, ou seja, com parasitológico positivo, a IDRM apresentou sensibilidade de $96,0 \%$ e a IFI de $75,7 \%$. Esta sensibilidade está próxima a obtida $(75 \%)$ por Silveira et al23. Já no primeiro mês de evolução da lesão, $97,6 \%$ dos pacientes apresentaram a IDRM positiva e 68,3\% tiveram títulos significativos de anticorpos pela IFI, mostrando a importância da utilização destas técnicas para o diagnóstico laboratorial mesmo em portadores de lesão recente.

A maioria $(92,3 \%)$ dos pacientes com diagnóstico positivo apresentava a forma cutânea da doença. Guimarães et al7 no Estado de São Paulo, e Barros et al3 na Amazônia, observaram 
percentuais semelhantes, enquanto Barreto et al9 no Estado da Bahia, relataram $67,1 \%$ de pacientes apresentando apenas formas cutâneas.

Apesar da ocorrência da forma nasobucofaríngea na região norte do Paraná, não foram observados casos com lesões mucosas múltiplas como os descritos por Marsden16. A maioria dos pacientes que apresentavam esta manifestação tinha história de lesão cutânea prévia. O intervalo de tempo entre a lesão cutânea e o aparecimento do comprometimento nasobucofaríngeo foi de até dois anos em 30,4\% dos pacientes e superior a dez anos em $50,0 \%$, diferindo dos dados descritos por Cuentas et al 5 no Estado da Bahia.

Em 58,1\% dos pacientes com comprometimento nasobucofaríngeo estudados neste trabalho os títulos de anticorpos pela IFI foram inferiores a 40 . Estes resultados concordam com os obtidos por Marsden 16 que relatou casos de indivíduos com lesões mucosas e testes intradérmicos negativos ou de lesões mucosas mas com títulos de anticorpos persistentemente negativos.

Os serodemas 1 e 3 de $L$. (V.) braziliensis foram os mais isolados dos pacientes autóctones do Paraná, sendo $49(63,6 \%)$ serodema 1 e 24 $(31,2 \%)$ serodema 3 . Uma das amostras pertence a um novo serodema de $L$.(V.) braziliensis caracterizado pelo epitopo N3, até agora, encontrado apenas em amostras da região andina do Peru, onde é muito comum (JJ Shaw, E Ishikawa, R Lainson, FT Silveira, CA Hanham: dados não publicados). Em outras áreas do Brasil a proporção do serodemas desta mesma espécie é diferente da que foi encontrada no Paraná. Na Bahia e Minas Gerais até o momento, $100 \%$ das amostras de L.(V.) braziliensis pertencem ao serodema 1. Na Amazônia existe um maior número de serodemas.

Os dados apresentados neste trabalho confirmam que a leishmaniose tegumentar é endêmica no norte do Estado do Paraná, conforme foi observado anteriormente 24262733 . A doença ocorre em crianças e mulheres, havendo possibilidades de transmissão domiciliar e peridomiciliar. A maioria $(98,7 \%)$ das cepas identificadas era Leishmania ( $V$.) braziliensis e uma $(1,3 \%)$ amostra foi identificada como Leishmania (L.) amazonensis. Estas observações nos levam a enfatizar que a associação das técnicas de intradermorreação de Montenegro, imunofluorescência indireta e pesquisa direta do parasita, torna mais seguro o diagnóstico laboratorial da leishmaniose tegumentar. Este fato aponta para a necessidade de treinamento dos profissionais da área de saúde e de adequação dos laboratórios da rede pública e privada para o diagnóstico da leishmaniose tegumentar, no Estado do Paraná, uma vez que ele não é feito rotineiramente na maioria destes laboratórios.

\section{AGRADECIMENTOS}

Nossa gratidão à Dra Mariza Mendes Lacerda Shaw pelas suas críticas, comentários e sugestões.

\section{REFERÊNCIAS BIBLIOGRÁFICAS}

1. Arraes SMAA, Silveira TGV, Lonardoni MVC, Ramos M, Bertolini DA, Dias MLGG. Avaliação da intradermorreação de Montenegro: comparação entre dois antígenos de diferentes procedências. Revista Unimar 13:5-10, 1991.

2. Barreto AC, Cuba CAC, Marsden PD, Vexenat JA, Belder M. Características epidemiológicas da leishmaniose tegumentar americana em uma região endêmica do Estado da Bahia, Brasil. I. Leishmaniose humana. Boletín de la Oficina Sanitaria Panamericana 90:415-423, 1981.

3. Barros MLB, Paes MG, Talhari S. Leishmaniose cutâneo-mucosa na Amazônia. Anais Brasileiros de Dermatologia 57:153-154, 1982.

4. Camargo ME. Introdução às técnicas de imunofluorescência. Instituto de Medicina Tropical de São Paulo, 1973.

5. Cuentas EAL, Cuba CAC, Barreto AC, Marsden PD. Clinical characteristics of human Leishmania braziliensis braziliensis infections. Transactions of the Royal Society of Tropical Medicine and Hygiene 78:845-846, 1984.
6. Fundação Nacional de Saúde. Número de casos notificados de leishmaniose tegumentar americana. Residentes na UF, segundo Unidade Federada, Brasil 1994. Ministério da Saúde. S.L.: s.n., [1996?]. Mimeogr.

7. Fundação Nacional de Saúde. Casos notificados de leishmaniose tegumentar americana. Residentes na UF, por ano, segundo Unidade Federada. Brasil, Brasil 1980 a 1994. Ministério da Saúde. S.L.: s.n., [1995?]. Mimeogr.

8. Grimaldi Jr G, Tesh RB, McMahon-Pratt D. A review of the geografic distribution and epidemiology of leishmaniasis in the new World. American Journal of Tropical Medicine and Hygiene 41: 687-725,1989.

9. Guimarães MCS, Celeste BJ, Camargo ME, Dinerz JM. Seroepidemiology of cutaneous leishmaniasis from Ribeira do Iguape Valley, IgM and IgG antibodies detected by means of an immunoenzymatic assay (ELISA). Revista do Instituto de Medicina Tropical de São Paulo 25:108112, 1983. 
10. Guimarães MCS, Giovannini VL, Camargo ME. Antigenic standardization for mucocutaneous leishmaniasis immunofluorescence test. Revista do Instituto de Medicina Tropical de São Paulo 16:182-188, 1974.

11. Lacerda MM. The Brazilian Leishmaniasis Control Program. Memórias do Instituto Oswaldo Cruz 89:489495. 1994.

12. Lainson R. Our present knowledge of the ecology and control of leishmaniasis in the Amazon region of Brazil. Revista da Sociedade Brasileira de Medicina Tropical 18:47-56, 1985.

13. Lima EC, Luz E, Souza LA. Leishmaniose tegumentar americana no município de Fóz do Iguaçu. Revista Médica do Paraná 27:53-58, 1958.

14. Lonardoni MVC, Teodoro U, Arraes SMAA, Silveira TGV, Bertolini DA, Ishikawa EAY, Shaw JJ. Nota sobre leishmaniose canina no noroeste do Estado do Paraná, sul do Brasil. Revista de Saúde Pública 27:378-379, 1993.

15. Marsden PD. Pentavalent antimonials: old drugs for new diseases. Revista da Sociedade Brasileira de Medicina Tropical 18:187-198, 1985.

16. Marsden PD. Mucosal leishmaniasis ("espundia" Escomel, 1911). Transaction of the Royal Society of Tropical Medicine and Hygiene 80:859-876, 1986.

17. Miranda RN, Schweidson JA. Leishmaniose tegumentar no Paraná. Revista Médica do Paraná 24:5-6, 1955.

18. Pessôa SB, Barretto MP. Leishmaniose tegumentar. Rio de Janeiro. Serviço de Documentação do Ministério da Educação e Saúde. Imprensa Nacional, 1948.

19. Secretaria de Estado da Saúde. Série histórica de casos de leishmaniose tegumentar no Paraná. S.I.: s.n.[1996?]. Mimiógr.

20. Roberto ACBS, Lima AP, Peixoto PR, Misuta NM, Fukushigue Y, Ferreira MEMC, Nerilo Sobrinho A, Silveira TGV, Teodoro U. Avaliação da terapia com antimoniato de N-Metil Glucamina e de notificação de leishmaniose tegumentar. Anais Brasileiros de Dermatologia 72:129136, 1997.

21. Shaw JJ, Ishikawa EA, Lainson R. A rapid and sensitive method for the identification of Leishmania with monoclonal antibodies using fluorscein-labelled avidin. Transaction of the Royal Society of Tropical Medicine and Hygiene 83:783-784, 1989.

22. Shaw JJ, Lainson R, McMahon-Pratt D, David JR. Serodemes of the Leishmania braziliensis complex. In: Rioux J (ed) Leishmania Taxonomie et phylogenése. Applications éco-épidémiologiques. Colloque International, IMEEE, Montpellier, pp. 179-183, 1986.

23. Silveira TG, Arraes SM, Pereira DS, Lonardoni MV, Dias ML, Ramos M, Bertolini DA, Fressatti R, Misuta NM. Avaliação da reação de imunofluorescência indireta para leishmaniose tegumentar americana em pacientes da região norte noroeste do Estado do Paraná - Brasil. Revista Unimar 12:177-188, 1990.

24. Silveira TG, Lonardoni MV, Arraes SM, Bertolini DA, Ramos M, Teodoro U. Leishmaniose tegumentar americana - aspectos epidemiológicos no norte do Estado do Paraná - Brasil. In: IV Encontro Científico da Universidade Estadual de Maringá, Maringá, 1992.

25. Silveira TG, Teodoro U, Arraes SM, Lonardoni MV, Dias ML, Shaw JJ, Ishikawa EA, Lainson R. An autochthonous case of cutaneous leishmaniasis caused by Leishmania (Leishmania) amazonensis Lainson \& Shaw, 1972 from the north of Paraná State, Brazil. Memória do Instituto Oswaldo Cruz 85:475-476, 1990.

26. Silveira TG, Teodoro U, Lonardoni MV, Guilherme AL, Toledo MJO, Ramos M, Arraes SM, Bertolini DA, Spinosa RP, Barbosa OC. Aspectos epidemiológicos da leishmaniose tegumentar em área endêmica do Estado do Paraná, Brasil. Cadernos de Saúde Pública 12:141$147,1996$.

27. Silveira TG, Teodoro U, Lonardoni MV, Toledo MJO, Vedovello Filho D, Bertolini DA, Arraes SM, Guilherme AL. Investigação sorológica em cães de área endêmica de leishmaniose tegumentar, no Estado do Paraná, Sul do Brasil. Cadernos de Saúde Pública 12:89-93,1996.

28. Superintendência de Campanhas (SUCAM). Leishmaniose tegumentar americana no Brasil: sua problemática, seu controle, desafios e perspectivas. Informativo epidemiológico da SUCAM, Ministerio da Saúde. 5(50):1987.

29. Superintendência de Campanhas (SUCAM). Relatório da Reunião Técnico Operacional Sobre o Controle da Leishmaniose Tegumentar Americana. Ministério da Saúde. Brasília, 1988.

30. Teodoro U. Características ecológicas de flebotomíneos (Diptera - Psychodidae) em habitats antrópicos, município de Jussara, Paraná, Brasil. Tese de doutorado, Universidade Federal do Paraná, Curitiba, PR, 1995.

31. Teodoro U, La Salvia Filho V, Lima EM, Spinoza RP, Barbosa OC, Ferreira ME, Lonardoni MV. Observações sobre o comportamento de flebotomíneos em ecótopos florestais e extraflorestais, em área endêmica de leishmaniose tegumentar americana, no norte do Estado do Paraná, sul do Brasil. Revista de Saúde Pública 27:242-249, 1993.

32. Teodoro U, Spinoza RP, La Salvia Filho V, Guilherme AL, Lima AP, Junqueira GM, Misuta NM, Nerilo Sobrinho A, Lima EM. Necessity to adopt and disseminate therapeutic schemes for the treatment of American tegumentary leishmaniasis in Paraná. Revista do Instituto de Medicina Tropical de São Paulo 33: 199-204, 1991.

33. Verzignassi TG, Pereira DS, Teodoro U, Misuta NM, Dias ML, Ferreira ME, Fressatti R, Aristides SMA. Leishmaniose tegumentar americana: aspectos epidemiológicos no norte do Paraná, Brasil. Ciência e Cultura 40:884, 1988. 
Revista da Sociedade Brasileira de Medicina Tropical 32:413-423, jul-ago, 1999.

34. Ward RD. New world leishmaniais: a review of the epidemiological changes in the last three decades. In:
Abstracts of $15^{\text {th }}$ International Congress of Entomology. Washington, DC,. Proceedings. p. 505-522, 1977. 